\title{
Calcitonin is expressed in gonadotropes of the anterior pituitary gland: its possible role in paracrine regulation of lactotrope function
}

\author{
Y Ren, J Chien, Y P Sun and G V Shah \\ Department of Pharmaceutical Sciences, Texas Tech University Health Sciences Center, 1300 Coulter, Amarillo, Texas 79106, USA \\ (Requests for offprints should be addressed to G V Shah, Texas Tech University Health Sciences Center, Department of Pharmaceutical Sciences, \\ 1300 Coulter, Amarillo, Texas 79106, USA; Email: girish@cortex.ama.ttuhsc.edu)
}

\begin{abstract}
Previous studies from this laboratory have shown that salmon (S) calcitonin (CT)-like immunoreactive peptide (CTI) is synthesized and secreted by the anterior pituitary (AP) gland. These studies also co-localized CTI to gonadotropes, and demonstrated that SCT is a potent inhibitor of lactotrope function. However, the molecular structure of putative gonadotrope-derived CTI that inhibits lactotrope function has not been defined.

The present studies cloned CT cDNA (pit-CT cDNA) from a mouse gonadotrope L $\beta$ T 2 cell line using RT-PCR and rapid amplification of cDNA ends (RACE) techniques. Alignment of nucleotide sequences of pit-CT and mouse CT revealed greater than 99\% homology between the sequences. The pit-CT cDNA was ligated into a mammalian expression vector, and the construct was transfected into L $\beta$ T2 cells. Two stable transfectant cell lines (CT.U6/A and B) were obtained by selection in
\end{abstract}

G418. Subsequent S1-nuclease protection assay and immunocytochemistry results have shown that: (1) pit-CT peptide expressed by CT.U6 cell lines immunoreacted with GCT1-anti-SCT serum; (2) secretions of CT.U6 cells inhibited prolactin (PRL) release, PRL mRNA abundance and DNA synthesis of PRL-secreting GGH3 cells; and (3) CT.U6-induced inhibition was abolished by GCT1-anti-SCT serum. The studies also generated a riboprobe from the cloned pit-CT cDNA, and localized $\mathrm{CT}$ mRNA expression in gonadotropes of rat AP gland by in situ hybridization histochemistry.

These results demonstrate that pit-CT mRNA is closely homologous to mouse CT mRNA; it is expressed by gonadotropes of the rat AP gland, and the peptide may significantly affect lactotrope function by inhibiting PRL release and cell proliferation.

Journal of Endocrinology (2001) 171, 217-228

\section{Introduction}

Calcitonins (CTs) are a group of polypeptide hormones containing 32 amino acid residues (Potts 1976, Stevenson 1980, Fischer \& Born 1985, Azria 1989). All share an amino terminal ring structure, with cysteines at 1 and 7 linked by a disulfide bridge, as well as a carboxy terminal prolinamide. CT-like immunoreactivity (CTI) is widely distributed in the CNS and the pituitary gland of various mammalian species including rats and humans (Watkins \& Moore 1980, Fischer et al. 1981, 1983, Flynn et al. 1981, Sexton \& Hilton 1992). Receptors recognizing salmon (S) $\mathrm{CT}$ have been detected in specific regions of rat brain and the anterior pituitary (AP) gland (Fischer et al. 1981, Henke et al. 1983, Sexton et al. 1993, Sheward et al. 1994), and complementary (c) DNAs for two such receptors have been cloned from a rat brain cDNA library (Albrandt et al. 1993). Supporting the physiological relevance of CT actions in the AP gland are the findings of the presence of SCTI and human (H) CTI in rat and human hypothalami and the pituitary glands by several investigators (Deftos et al. 1978, Margules et al. 1979, Cooper et al. 1980, Fischer et al. 1981, 1983, Flynn et al. 1981, Balabanova et al. 1985, Deftos 1987, Sexton \& Hilton 1992, Shah et al. 1993, Hilton et al. 1998). The evidence for the synthesis and secretion of CT-like immunoreactive peptides by primary cultures of the rat AP gland has also been presented (Deftos 1987, Shah et al. 1993). Pituitary derived CT (pit-CT) may share antigenic sites with human (or rat) CT (HCT) and SCT since antisera raised against these peptides immunoprecipitate molecules of similar electrophoretic mobility from AP cell lysates (Shah et al. 1993). Using GCT1, the anti-SCT serum raised in this laboratory, we have shown that CTI is selectively localized in gonadotropes, and not in thyrotropes, somatotropes, lactotropes, corticotropes or folliculo-stellate cells of rat AP gland (Shah et al. 1993, Chronwall et al. 1996).

Previous findings from this laboratory have shown that exogenously added SCT significantly attenuates prolactin 
(PRL) release from perifused rat $\mathrm{AP}$ cells without altering the secretion of growth hormone $(\mathrm{GH})$, folliclestimulating hormone, luteinizing hormone (LH) or thyroid stimulating hormone (Shah et al. 1988, 1990). SCT is also a potent inhibitor of PRL gene transcription and lactotrope cell proliferation in rats (Zhang et al. 1995, Shah et al. 1999). Interestingly, the addition of GCT1-anti-SCT serum immunoneutralizes endogenous CT, stimulates PRL release from cultured rat pituitary cells and raises serum PRL levels in conscious ovariectomized rats (Shah et al. 1993, 1996). These results raise the possibility that gonadotrope-derived GCT1-immunoreactive CT is a paracrine inhibitor of lactotrope function. Since the molecular sequence of gonadotrope-derived CT-like peptide that regulates lactotrope function has not been determined, we attempted to determine the identity of this important regulatory peptide. We report that we have cloned and sequenced CT cDNA from a mouse gonadotrope-derived L $\beta$ T2 cell line (Thomas et al. 1996). The study compared the cloned pit-CT cDNA sequence with mouse CT sequence, and also tested the effects of the encoded protein on PRL release, PRL gene expression and proliferation of rat somatomammotrope-derived GGH3 cell line. Additional studies co-localized pit-CT mRNA in rat AP gland by in situ hybridization histochemistry.

\section{Materials and Methods}

dCTP, $\left[{ }^{32} \mathrm{P}\right] \mathrm{dUTP}$ and ${ }^{125}$ I were purchased from DupontNew England Nuclear (Boston, MA, USA). Dulbecco's modified Eagle's medium (DMEM), RPMI-1640, penicillin G-streptomycin mixture, horse sera, fetal calf sera and Superscript II reverse transcriptase were obtained from Gibco Laboratories (Grand Island, NY, USA). PCR amplimers were synthesized by Genemed Synthesis, Inc. (San Francisco, CA, USA). Synthetic salmon (S) CT was obtained from Peninsula Laboratories (Belmont, CA, USA), and the rat PRL RIA kit was provided by the National Hormone and Pituitary Program (Harbor-UCLA Medical Centre, Torrance, CA, USA). All other chemicals were purchased from Sigma Chemical Co. (St Louis, MO, USA) unless otherwise stated.

\section{Cell lines}

L $\beta$ T2, a gonadotrope-derived mouse cell line that secretes $\alpha$ as well as $\beta$ subunits of $\mathrm{LH}$ was provided by Dr Pam Mellon (University of California San Diego, USA). The cells were maintained in the complete medium as recommended by Dr Mellon's group. The complete growth medium was prepared in DMEM containing $4.5 \mathrm{mg} / \mathrm{ml}$ glucose and supplemented with $10 \%$ fetal calf serum.

\section{Preparation of $R N A$ and $R T-P C R$}

Total RNA from L $\beta$ T2 cells was extracted using RNeasy Mini Kit (QIAGEN, Valencia, CA, USA). One microgram total RNA was used for reverse transcription (RT). Oligo dT primer annealing and reverse transcription were performed using Superscript II reverse transcriptase according to the manufacturer's protocol (GIBCO-BRL, Gaithersburg, MD, USA).

\section{Polymerase chain reaction (PCR)}

Reverse transcribed cDNA was amplified with a PCR reagent kit purchased from Gibco-BRL. Since HCT-like as well as SCT-like peptides have been detected in the AP gland (Gagel et al. 1983, Sexton \& Hilton 1992, Shah et al. 1993, Hilton et al. 1998), we used two sets of primer pairs derived from either mouse $(\mathrm{m})$ or SCT $\mathrm{cDNA}$ sequences: mCT-forward: $5^{\prime}$-agagtcaccgcttcgcaa-3'; mCT-reverse: $5^{\prime}$-ccagagaggaactacatgcatc- $3^{\prime}$; SCT-forward: $5^{\prime}$-gcaagcaag atccacatg-3'; SCT-reverse: $5^{\prime}$-agagcaaccgctatgcaagcta- $3^{\prime}$.

The hot start method was employed to minimize non-specific amplification. The amplified product or products were fractionated on a 1\% agarose gel, the bands were cut, and the DNA was extracted and subcloned in pGem-T vector (Promega Laboratories, Milwaukee, WI, USA). The recombinant plasmids were sent for DNA sequencing at the Texas Tech University Biotechnology Facility.

\section{RACE and screening}

The first series of PCR reaction yielded two clones that were highly homologous to the mouse CT sequence. Since these sequences were partial, RACE reaction was employed to obtain longer sequences. The gene specific primer (GSP) (5'-caaggatcaagagtcaccgcttcgcaagcactgcct ggc- $3^{\prime}$ ) and universal primer mix (CLONTECH, Palo Alto, CA, USA) were used for $3^{\prime}$-RACE. The reaction was first cycled 5 times $\left(5 \mathrm{~s}, 94^{\circ} \mathrm{C} ; 3 \mathrm{~min}, 72^{\circ} \mathrm{C}\right)$, and cycled 5 times again $\left(5 \mathrm{~s}, 94{ }^{\circ} \mathrm{C} ; 10 \mathrm{~s}, 70{ }^{\circ} \mathrm{C} ; 3 \mathrm{~min}, 72{ }^{\circ} \mathrm{C}\right)$ based on the manufacturer's recommendations, and then subjected to 30 cycles of PCR $\left(5 \mathrm{~s}, 94^{\circ} \mathrm{C} ; 10 \mathrm{~s}, 60{ }^{\circ} \mathrm{C}\right.$; $2 \mathrm{~min}, 72^{\circ} \mathrm{C}$ ). PCR products were purified with a DNA purification kit (Bio-RAD, Hercules, CA, USA) and ligated into the pGEM-T vector. Plasmid DNA from several clones was prepared and identified by Southern blotting using the partial CT cDNA probe. Positive RACE clones were sent for DNA sequencing.

\section{Expression of recombinant pit-CT in L $\beta T 2$ cells}

pit-CT cDNA insert was cloned downstream of the cytomegalovirus promoter in pcDNA3.1/Myc-His $(+) \mathrm{B}$ vector (Invitrogen, San Diego, CA, USA). The presence and orientation of the insert in the recombinant plasmid (pcDNA3·1-CT) was verified by digestion with appropriate restriction enzymes as well as by DNA sequencing of the insert. Vector pcDNA3.1 has two distinct C-terminal epitopes to detect the recombinant proteins. The 
C-terminal of the expressed protein will carry a $c-m \gamma c$ epitope that can be identified by anti-myc antibody. This epitope is followed by a polyhistidine tag, which can be identified by anti-His (C-term) antibody.

The recombinant plasmid was then used for transfection in L $\beta$ T2 cells. L $\beta$ T2 cells in mid-to-late log phase were harvested and resuspended in ice-cold PBS at 10 million cells $/ \mathrm{ml}$, and mixed with plasmid DNA (recombinant plasmid pcDNA 3.1-CT or vehicle plasmid pcDNA $3 \cdot 1,30 \mu \mathrm{g} / \mathrm{ml}$ ) in an electroporation cuvette, and electroporated at $800 \mu \mathrm{F}$ and $250 \mathrm{~V}$ (Gene Pulser II, Bio-RAD). Transfected cells were incubated in a 6-well plate with DMEM for $48 \mathrm{~h}$ and then selected with $400 \mu \mathrm{g} / \mathrm{ml} \mathrm{G} 418$. Individual colonies were selected after four weeks of culture, dispersed with trypsin/EDTA and propagated further into fresh flasks. Two cell colonies, CT.U6/A and CT.U6/B, displaying the highest CTI secretion were chosen for further investigation.

\section{Detection of CT mRNA in CT-transfectants}

The cell lines L $\beta$ T2 (parental), V (carrying vehicle plasmid), CT.U6/A and CT.U6/B were cultured as described above. Three hundred thousand cells of each of these cell lines were seeded individually into $100 \mathrm{~mm}$ dishes, and were grown to exponential phase. The total RNA from these cell lines was extracted as previously described (Xie \& Rothblum 1991), and was used to determine CT mRNA abundance by S1-nuclease protection assay.

\section{S1-nuclease protection assay}

UTP-labeled antisense riboprobes of pit-CT, PRL and $\beta$-actin were generated using T7 RNA polymerase (Promega) and appropriate linearized DNA templates. Total RNA $(20 \mu \mathrm{g})$ was incubated with the appropriate riboprobe for $18 \mathrm{~h}$ at $45^{\circ} \mathrm{C}$. Following this, the samples were treated with $\mathrm{S} 1$-nuclease for $30 \mathrm{~min}$ at $37^{\circ} \mathrm{C}$. The protected RNA was precipitated and fractioned on $4.5 \%$ polyacrylamide gel with $8 \mathrm{M}$ urea. The gel was then dried and autoradiographed. Each experiment was repeated three separate times.

\section{Secretion of CTI in the conditioned media}

Levels of CTI and PRL in the conditioned media of L $\beta$ T2 cells and CT-transfectants were determined by RIA. The PRL RIA used the reagents provided by the NIDDK, and the assay protocol recommended by the NIDDK was followed. CTI was determined as described previously (Shah et al. 1989). All samples from this series of experiments were concurrently run in duplicate in the same RIA. Protein A (IgG Sorb) was used for the separation of bound from free hormone antigen. The experiments were repeated at least three separate times, and data from all the experiments were pooled for statistical analysis.

\section{CT immunocytochemistry (ICC)}

Approximately 10000 L $\beta$ T2 cells or CT-transfectants were plated onto polylysine-coated microscope slides. The cells were incubated for $18 \mathrm{~h}$ at $37^{\circ} \mathrm{C}$, washed with PBS and fixed for $1 \mathrm{~h}$ in Zamboni's solution. The fixed cells were processed for pit-CT ICC as previously described except that the second antibody was conjugated to horseradish peroxidase (HRP) and therefore the color was developed using diaminobenzidine tetrahydrochloride (DAB) as a substrate (Chronwall et al. 1996). The negative controls were treated with primary antiserum that was preincubated with $1 \mu \mathrm{M}$ SCT at $37^{\circ} \mathrm{C}$ for $1 \mathrm{~h}$. The experiments were repeated two more times.

\section{Immunodetection of recombinant pit-CTI by Western blot using GCT1 and anti-His antibodies}

Crude cell lysates from the parental L $\beta$ T2 cells and CT.U6 (A and B) were prepared as previously described (Chien et al. 1999). In brief, 10 million cells from each cell line were homogenized in Buffer A (25 mM Tris, $\mathrm{pH} 7 \cdot 4$ containing 10\% glycerol, $1 \%$ Nonidet P-40, $50 \mathrm{mM}$ $\mathrm{NaF}$ and freshly supplemented with $10 \mathrm{mM}$ sodium pyrophosphate (PPi), $1 \mathrm{mM}$ sodium vanadate, leupeptin $(10 \mu \mathrm{g} / \mathrm{ml})$, aprotinin $(5 \mu \mathrm{g} / \mathrm{ml})$, and phenylmethylsulfonyl fluoride $(1 \mathrm{mM}))$. Nuclear fraction and debris were separated by centrifugation at $2000 \mathrm{~g}$ for $10 \mathrm{~min}$ at $4{ }^{\circ} \mathrm{C}$, and the supernatant was used for Western blot analysis. Protein concentrations of cell lysates were determined using Bio-Rad protein reagent (Hercules, CA, USA). The lysates were then boiled for $5 \mathrm{~min}$ in $2 \times$ Laemmli solution containing $20 \mathrm{mM}$ dithiothreitol (DTT), and $50 \mu \mathrm{g}$ protein per lane were loaded onto $12 \cdot 5 \%$ SDS-polyacrylamide gel. The separated proteins were electrically transferred to nitrocellulose, and the blots were incubated with previously characterized GCT1 rabbit anti-SCT serum $(1: 500)$ as well as mouse anti-histamine serum (Cterminal, 1:3000, Invitrogen, San Diego, CA, USA) for $18 \mathrm{~h}$ at $4{ }^{\circ} \mathrm{C}$. Following three washes, the membranes were incubated with either anti-rabbit or anti-mouse IgG-HRP (1:1000). Following three successive washes, the immune complexes were visualized using Western blot ECL detection system (Radiochemical Center, NEN Life Science Products, Boston, MA, USA). The same experiment was repeated one more time.

\section{Biological activity of recombinant pit-CT: co-culture of CT-transfectants and GGH3 cells and its effect on PRL secretion, PRL $m R N A$ abundance and DNA synthesis of GGH3 cells}

To further examine the role of pituitary-derived CT in lactotrope function, we developed a two-tier co-culture 
system where $110^{5}$ L $\beta$ T2 cells or CT transfectants (CT.U6/A or CT.U6/B) are cultured separately in an upper chamber insert, whereas $2 \times 10^{5} \mathrm{GGH} 3$ cells per well (target cells) are cultured in a 12-well plate. During the experimental period, the upper chamber is inserted on top of a well of a 12-well plate containing GGH3 cells so that CT-secretors (in the upper chamber) do not come in direct contact with GGH3 cells (in the lower chamber) but are exposed to their secretions. The GGH3 cells in each set of the experiment were treated as follows: (1) vehicle control where the upper chamber contained GGH3 cells instead of CT-secretors $+10 \mu \mathrm{l}$ non-immune serum (NIS) in the lower chamber; (2) upper chamber contained either L $\beta$ T2 or CT.U6 (A or B), and $10 \mu \mathrm{l}$ NIS were added in the lower chamber; and (3) upper chamber contained either LBT2, CT.U6/A or CT.U6/B cells, and $10 \mu \mathrm{l}$ anti-SCT serum were added to the medium in the lower chamber. After the incubation period of $24 \mathrm{~h}$, either the conditioned media or GGH3 cells in the lower chamber were harvested. The conditioned media were analyzed for PRL by RIA. The cell lysates were used to analyze PRL mRNA abundance as described in the S1-nuclase protection assay. Each data point was run in triplicate and the data from three independent but similar experiments were obtained.

The results on PRL release are expressed as ng PRL released by 100000 cells over $24 \mathrm{~h}$. The results on PRL mRNA were digitized, normalized with $\beta$-actin mRNA and expressed as normalized densitometric units. The data from all experiments were pooled and expressed as means \pm s.E.M. The results were statistically evaluated by one-way ANOVA and the significance was derived by Newman-Keul's test.

\section{$\left.{ }^{3} H\right]$ Thymidine incorporation of GGH3 cells}

GGH3 cells in log phase were seeded at $1 \times 10^{5}$ cells/well in $1 \mathrm{ml}$ complete medium in 12-well culture plates. The growth rate of cells was slowed down by overnight incubation in low-serum-containing medium ( $2 \%$ FCS) followed by 2 -h incubation in serum-free basal medium. The cells were then co-incubated with CT-transfectants as described above for $24 \mathrm{~h}$. Four hours prior to the termination of the assay, the GGH3 cells (in the lower chamber) received $\left[{ }^{3} \mathrm{H}\right]$ thymidine $(0 \cdot 5 \mu \mathrm{Ci} /$ well). At the end of the incubation, the cells were washed twice with PBS containing $100 \mu \mathrm{M}$ unlabeled thymidine, and solubilized in Triton X-100 $(0 \cdot 1 \% \mathrm{vol} / \mathrm{vol}$ in distilled water). The incorporated $\left[{ }^{3} \mathrm{H}\right]$ thymidine was quantified by liquid scintillation counting. Each data point was run in quadruplicate and the data from three independent but similar experiments were obtained.

The results are expressed as d.p.m. of $\left[{ }^{3} \mathrm{H}\right]$ thymidine incorporated per $1 \times 10^{5}$ cells \pm S.E.M. The data from all experiments were pooled and analyzed by one-way
ANOVA and the level of significance was derived from Newman-Keul's test.

Localization of pit-CT $m R N A$ in rat AP gland: in situ hybridization histochemistry (ISH)

Preparation of sense/anti-sense digoxigenin-labeled pit-CT riboprobes Plasmid containing partial CT.U6 (86-580) was linearized, and antisense riboprobe was transcribed using T7 RNA polymerase. Similarly, a sense riboprobe was generated using SP6 RNA polymerase. Digoxigenin 11-UTP (Boehringer Mannheim, Indianapolis, IN, USA) was used in both transcription reactions, and the manufacturer's instructions were followed. The reaction mixtures were digested with RNAse-free DNAse (Boehringer), the riboprobes were extracted with phenol/chloroform, and purified on TE microselect-D G-50 spin columns (5 Prime-3 Prime, Inc., Boulder, CO, USA).

Preparation of LH- $\beta$ and PRL cDNA-rhodamine probes cDNA inserts for rat LH- $\beta$ or rat PRL were labeled with tetramethyl rhodamine-6-dUTP by random primer labeling using klenow fragments of DNA polymerase (Feinberg \& Vogelstein 1983), and the probes were purified on TE Microselect-D G-50 spin columns (5 Prime-3 Prime, Inc.).

\section{Double in situ hybridization histochemistry (ISH)} The rat AP glands were rapidly frozen by submersion in an isopentane-dry $\mathrm{CO}_{2}$ bath after mounting in the embedding medium (OCT compound, Tissu-Tek, Miles Laboratories, Elkhart, IN, USA). The frozen tissues were sliced to 5-10 $\mu \mathrm{m}$ thick sections and thaw-mounted on Superfrost plus glass slides (Fisher Scientific, Pittsburgh, PA, USA). The sections were stored frozen at $-70{ }^{\circ} \mathrm{C}$ until ISH analysis.

The frozen tissue sections were rapidly thawed, washed with PBS at $4{ }^{\circ} \mathrm{C}$, and fixed in $4 \%$ paraformaldehyde-PBS $(\mathrm{pH} 7 \cdot 2)$ for $10 \mathrm{~min}$. The double ISH procedure was performed using antisense pit-CT RNA and LH- $\beta$ or PRL cDNA probes as described before (Iczkowski et al. 1998). Serial sections of the specimens were concurrently probed with sense probes, which served as negative controls. The hybridization signal of CT mRNA was detected by incubating the hybridized sections with mouse anti-digoxigenin-FITC for $6 \mathrm{~h}$ at $4{ }^{\circ} \mathrm{C}$, whereas the cDNA probes for LH- $\beta$ or PRL contained fluorescent ribonucleotide and did not need additional processing. Three animals per group were used for these experiments. Sections from all animals were processed simultaneously. Two researchers independently evaluated the slides, scoring all slides at the same time to avoid comparing preparations that had been stored or exposed to UV-light for different periods of time. The sections (at least twelve/ experiment from three different animals) were observed 
under a Nikon Optiphot microscope with epifluorescence attachment. The digital images were captured on a G3 Power PC computer by a Spot camera attached to the microscope and examined for co-localization between pit-CT mRNA and LH- $\beta$ or PRL mRNA.

\section{Results}

Amplification and sequencing of pit-CT $m R N A$ from $L \beta T 2$ cells

Initial PCR experiments with $\mathrm{mCT}$ amplimers yielded a partial cDNA of $564 \mathrm{bp}$ length. The cDNA sequence displayed greater than $90 \%$ homology with mouse CT mRNA sequence (emb/X97991-1). Thereafter, the deduced amino acid sequence of the known mouse CT was aligned with partial pit-CT sequence, and the conserved region was used to design a specific primer for $3^{\prime}$-RACE. First-strand cDNA produced by RT with $3^{\prime}$-CDS primer and universal primer mix was used as template for 3'-RACE. 3'-RACE products were ligated into pGEM-T vector. Nineteen clones were identified by Southern blotting and DNA sequencing. The alignment of nucleotide sequences revealed that a clone, pit-CT.U6, had greater than 99\% homology with the 23-829 bp segment of mouse CT mRNA (emb/X97991-1) (Fig. 1). Only seven out of 806 bases in the pit-CT mRNA sequence differed from mouse CT mRNA sequence. The mismatches were at positions 383, 418, 463, 469, 580, 831 and 851 of mouse CT sequence. Homology with rat calcitonin gene-related protein (CGRP) sequence was much less and covered only 58-232 bp segment of rat $\alpha$ CGRP mRNA (emb/V01229-1). Moreover, the presence of exon 4 in the pit-CT sequence, which is specific for CT but not CGRP, suggests that the CT gene of L $\beta$ T2 cells transcribes CT, and not CGRP, mRNA.

\section{Stable L $\beta T 2-C T$ transfectants express pit-CT $m R N A$ and GCT1-immunoreactive CT}

Cell clones CT.U6/A and CT.U6/B were obtained by selecting L $\beta$ T2 transfectants with G418. The results from S1-nuclease protection assay showed that CT.U6 (A and B) cells displayed markedly greater abundance of pit-CT mRNA than the parental L $\beta$ T2 cells (Fig. 2). Relative densitometric value of pit-CT mRNA in CT.U6 cells increased by $97 \%$ over parental L $\beta$ T 2 cells.

Since pcDNA3·1/Myc-His(+)B vector expresses fusion protein, the recombinant pit-CT.U6 protein should also express fusion protein poly Myc-His. The results from Western blot analysis of transfectants reveal that anti-His antibody identified three major immunoreactive bands in CT.U6 lysates (Fig. 3). However, the band with the highest molecular size was also observed in control L $\beta$ T2 cells which did not express the recombinant protein, and may be a plasmid-related band. Two other bands were specific for CT.U6 transfectants. Interestingly, GCT1 antiserum also identified these two molecular species, suggesting that fusion proteins in these two bands contain the encoded pit-CT peptide that cross-reacts with GCT1-anti-SCT serum.

Consistent with the results from Western blot analysis, ICC results also show that both CT.U6 clonal cell lines (A and B) stained strongly for CTI (GCT1). In contrast, control L $\beta$ T2 cells were only weakly positive (Fig. 4).

\section{Secretion of CTI by CT.U6 cells}

Results from CT RIA of spent media suggest that CT.U6 cell lines released $122 \cdot 47 \mathrm{pg} / 100000$ cells of CT-Eq in $24 \mathrm{~h}$. The corresponding release from control L $\beta$ T2 cells was very close to the detection limit of the assay (30 pg CT-Eq).

\section{CT.U6 cells inhibit PRL $m R N A$ and PRL release from GGH3 cells}

To test whether the actions of pit-CT on lactotrope function are consistent with previously demonstrated actions of GCT1-reactive CT, we developed a two-tier co-culture system where GH3 cells received secretions of either L $\beta$ T2 or CT.U6 cells but did not come in direct contact with them. As presented in Figs 5 and 6, secretions of both CT.U6 cell lines (A and B) caused a dramatic inhibition in PRL secretion as well as PRL mRNA levels. Parental L $\beta$ T2 cells also caused a decrease in PRL mRNA abundance and PRL release, but the decrease was smaller compared with that caused by CT.U6 cell lines.

Secretions from CT.U6 cells inhibit DNA synthesis of GG3 cells: this action is reversed by GCT1-anti-SCT serum

Since exogenously added CT inhibited proliferation of lactotropes under in vitro as well as in vivo conditions (Shah et al. 1999), we tested the effect of co-culture of CTtransfectants on DNA synthesis of GGH3 cells. The results presented in Fig. 7 show that $\left[{ }^{3} \mathrm{H}\right]$ thymidine incorporation in GGH3 cells cocultured with CT.U6 cell lines (bars 4 and 6) was dramatically lower when compared with the vehicle controls (bar 1). In parallel experiments, control L $\beta$ T2 cells were co-cultured with GGH3 cells. Similar to CT.U6 cells, L $\beta T 2$ cells also decreased DNA synthesis of GGH3 cells (bar 2). However, this inhibition was much smaller as compared with that produced by CTtransfectants (bar 2 vs bars 4 and 6). GCT1-anti-SCT antiserum almost abolished the inhibitory effect of L $\beta \mathrm{T} 2$ and CT.U6 cell lines on DNA synthesis of GGH3 cells (bars 3, 5, and 7).

\section{Localization of pit-CT $m R N A$ in gonadotropes of rat AP gland}

Since the pit-CT clone obtained from L $\beta T 2$ cells expressed 91\% homology with rat CT mRNA 


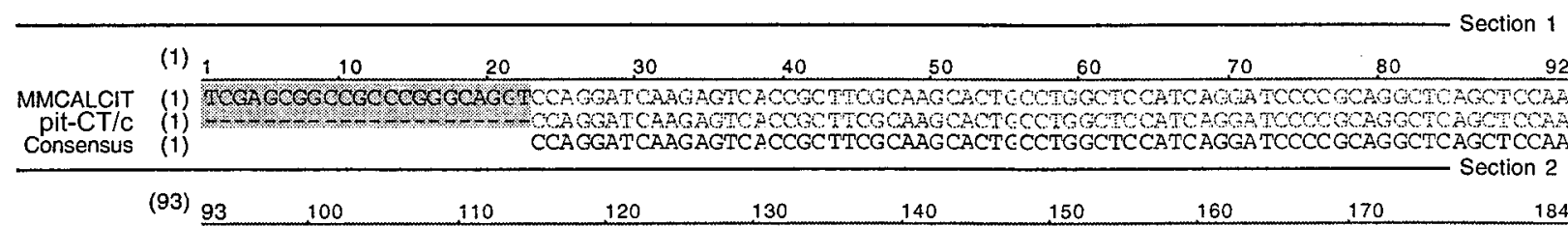

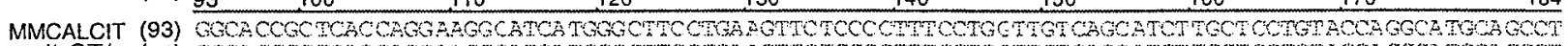

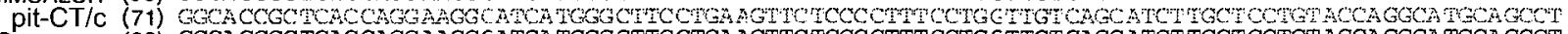
consensus (93) GGCACCGCTCACCAGGAAGGCATCA TGGGCTTCCTGA AGTTCTCCCCTTTCCTGGTTGTCAGCATCT TGCT CCTGT ACCA GGCA TGCA GCCT

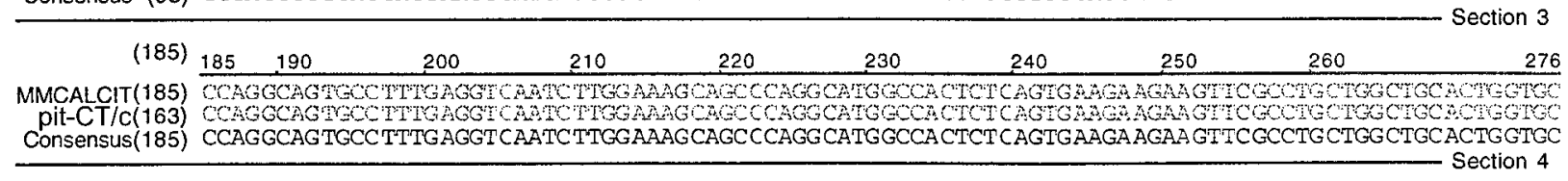
(277) 277
290
300
310
320
330
340
350
368

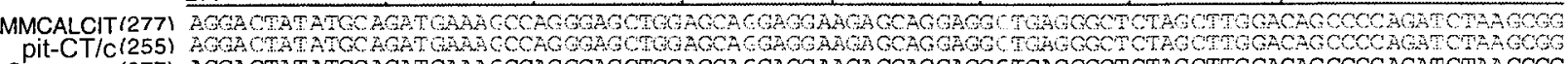
consensus(277) AGGACTATATGCAGATGAAACCCAGGGAGCTGGAGCA GGAGGAAGAGCAGGAGGCTGAGGGCTCTAGCTTGGACAGCCCCAGATCTAAGCGG COnsensuS(277) AGGACTATATGCAGATGAAACCCAGGGAGCMGAGCACGAGGAAGAGCAGGAGGCTGAGGGCICIAGCIIGGACAGCCCCAGATCIAAGCGG Section 5

(369) $\begin{array}{lllllll}369 & 380 & 390 & 400 & 410 & 420 & 430 \quad 40\end{array}$

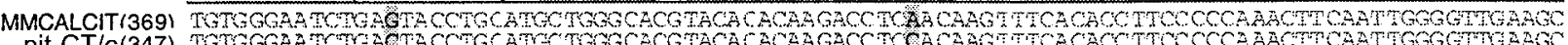
pit-CT/c(347) TG TGTGGAATCTGA TACCTGCATGCTGGGCACGTACACACAAGACCTC ACAAGTTCACACCTTCCCCCAAACTTCAATTGGGGTTGAAGC Consensus(369) TGTGGGAATCTGA TACCTGCATGCTGGGCACGTACACACAAGACCTC ACAAGTTTCACACC TTCCCCCAAACTTCAATTGGGGTTGAAGC

(461) 461 480 490 500 510 520 530 540 552

MMCALCIT(461) ACTGGC AaGA A

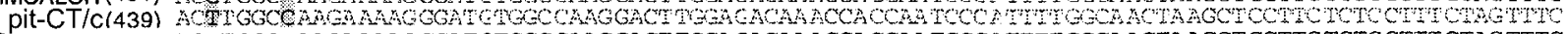
consensus(461) AC TGGC AAGAAAAGGGATGTGGCCAAGGACTTGGA GACAAACCA CCAA TCCCATTTTGGCA ACTAAGCTCCTTCTCTCCTT CTAGTTTC

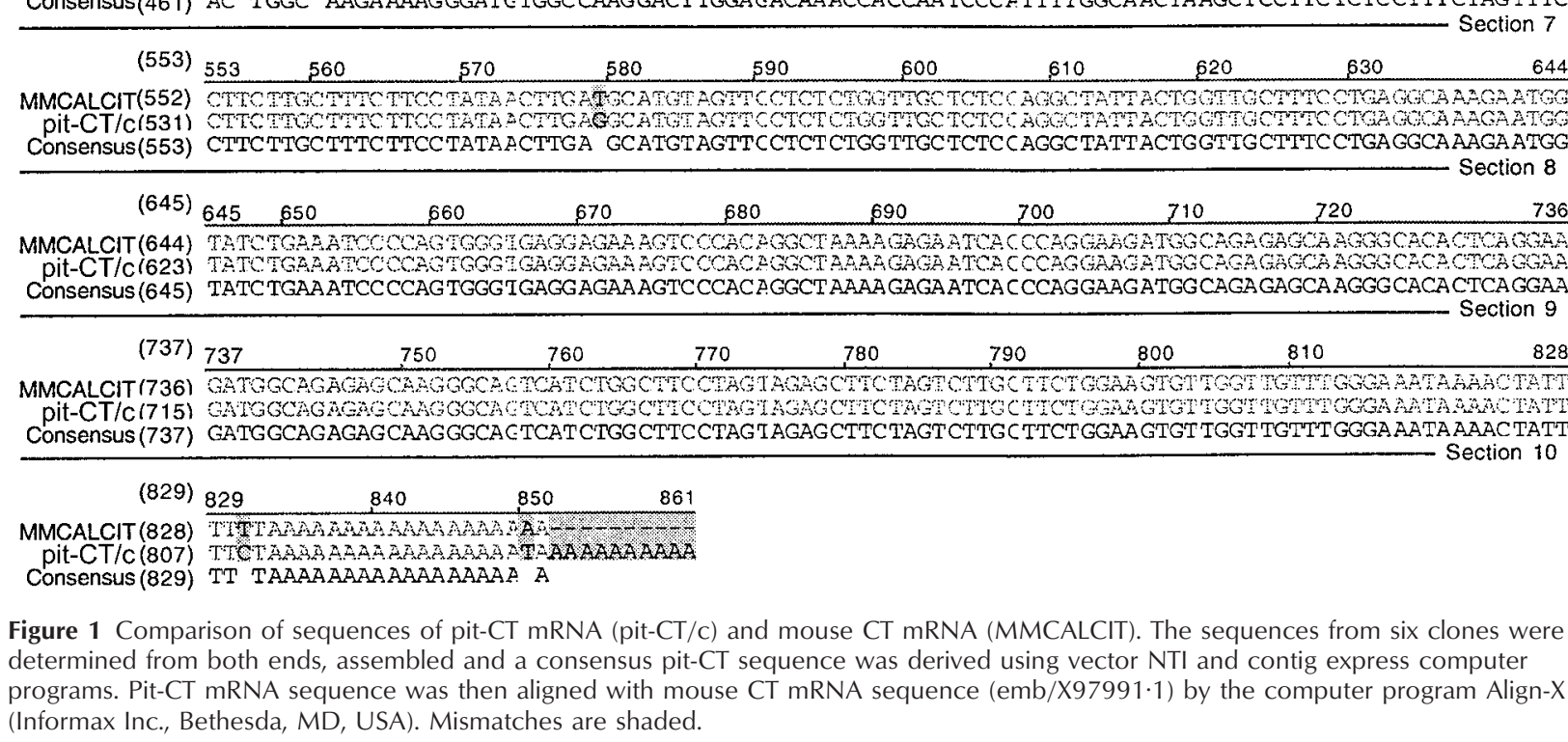

(gb/M26137-1), we constructed a partial pit-CT cDNA vector for riboprobe generation. The sequence of this pit-CT cDNA corresponded with the 4-493 bp segment of rat calcitonin mRNA (RCALC2), and displayed 92\% homology. The digoxigenin-UTP-labeled anti-sense probe was used for in situ hybridization histochemistry with frozen sections of the AP glands obtained from cyclic female rats in the diestrous phase. Approximately $7-8 \%$ of total AP cells displayed pit-CT message (lower panel of Fig. 8). A similar distribution profile was also observed for LH- $\beta$ mRNA (upper panel of Fig. 8), and co-localization of both these messages could be observed. Sense controls for CT as well as LH probes did not display significant staining (see insets on Fig. 8, lower and upper panels). These results are consistent with our previous findings using GCT1 and rat LH- $\beta$ antisera (Chronwall et al. 1996).

In another experiment, a relationship between CT cells and lactotropes was examined. The results presented in Fig. 9 show that CT mRNA-positive cells (green) were in apposition with PRL mRNA-positive cells (red). However, no co-localization of PRL and CT mRNA was observed. Again, sense controls did not display any 

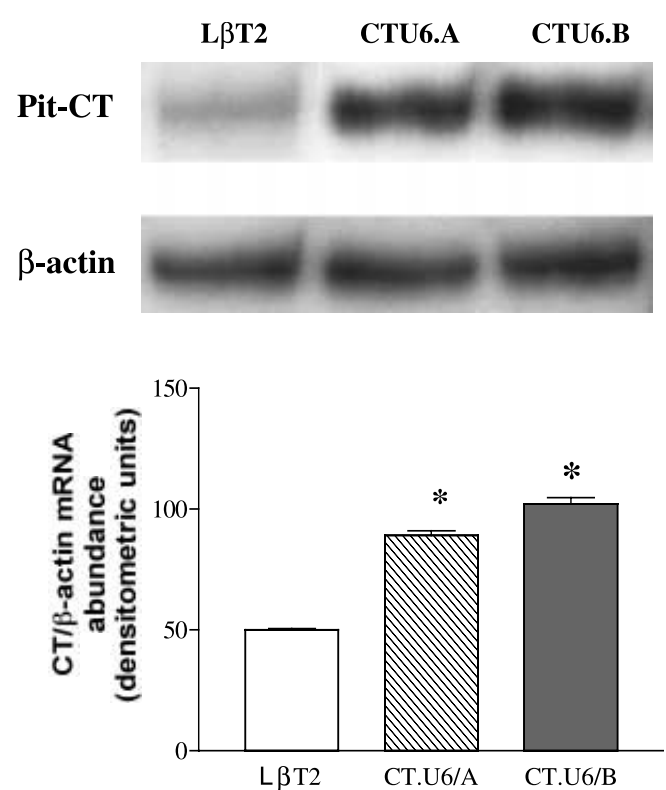

Figure 2 Overexpression of CT mRNA in stable CT.U6 transfectants. S1-nuclease protection assay showed that the CT.U6 cell lines (A and B) expressed higher levels of CT mRNA than parental $\mathrm{L} \beta \mathrm{T} 2$ cells. The data from three independent experiments were digitized to obtain relative densitometric units. Pooled data from these experiments showed an almost twofold increase in CT mRNA abundance of the transfectants as compared with parental $\mathrm{L} \beta \mathrm{T} 2$ cells. The results are expressed as means \pm S.E.M. densitometric units $(n=6)$. The data were analyzed by one-way ANOVA and significance was derived by Newman-Keul's test. ${ }^{*} P<0 \cdot 05$.

staining. These findings are also in agreement with our previously published results using GCT1-anti-SCT serum (Chronwall et al. 1996).

\section{Discussion}

Although there have been reports of the expression of CT-like peptides in the pituitary gland, these results for the

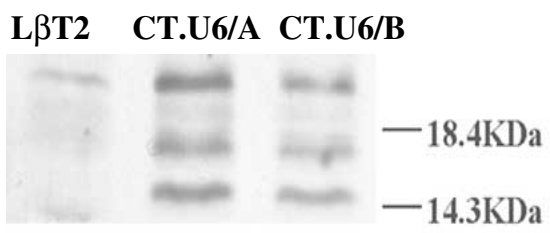

\section{Anti-His-IgG}

Figure 3 A typical profile of Western blotting of CT.U6 and parental L $\beta T 2$ cell extracts. Fifty micrograms cell lysate proteins were size-fractioned on $12.5 \%$ SDS-polyacrylamide gel. Following electric transfer, the nitrocellulose membranes were immunoblotted with anti-His antibody (Anti-His-IgG; left panel) and GCT1-anti-SCT antibody (GCT1-ASCT-Ab; right panel). Reactivity was demonstrated using ECL Western blotting detection reagents. Positions of protein markers are indicated on the right. Since pcDNA3·1/Myc-His(+)B vector expresses fusion protein, the expressed pit-CT.U6 peptide will be fused with poly Myc-His. Anti-His antibody detected two CT.U6 cell-specific immunoreactive bands. Interestingly, the same bands were also identified by GCT1-anti-SCT antibody. The experiment was repeated one more time, and a similar profile was observed. first time define the sequence of pituitary-derived CT. cDNA sequence of pit-CT showed greater than 99\% homology with mouse CT mRNA sequence (Rehli et al. 1996). It is conceivable that a few mismatches found in pit-CT sequence may have occurred due to spontaneous mutations known to occur in immortalized cell lines. It is also possible that Taq polymerase may have introduced mutation(s) during amplification. Additional studies with mouse AP glands will be necessary to explain these differences. However, the present results demonstrate that the mRNA sequence of pit-CT is closely homologous to mouse CT sequence, and the peptide encoded by the pit-CT mRNA immunoreacts with GCT1-anti-SCT serum. These results support our earlier observations that gonadotrope-derived CT immunoreacts with GCT1-antiSCT serum (Shah et al. 1993, 1996, Chronwall et al. 1996).

The second objective of the present study was to test whether pit-CT mRNA is localized in gonadotropes of rat AP gland. Using an anti-sense riboprobe derived from cloned pit-CT cDNA, the present results have shown that pit-CT mRNA is co-expressed with $\beta-\mathrm{LH}$ mRNA, and lactotropes (PRL mRNA-positive cells) display close anatomical apposition to pit-CT mRNA-positive cells. Both these results are consistent with our earlier findings (Chronwall et al. 1996). Although the presence of SCTlike and HCT-like immunoreactive peptides in the AP gland has been reported by several investigators, there is only one report on the detection of rat CT mRNA in this organ (Jacobs et al. 1982). The present results are at variance with the earlier study that reported the lack of detectable CT mRNA in rat AP gland. It is conceivable that low copy numbers of pit-CT mRNA in rat AP gland and utilization of the less sensitive Northern blot technique may have been responsible for this discrepancy. Indeed, we also could not detect pit-CT mRNA in rat AP gland by Northern blot analysis; however, the detection was possible with more advanced techniques such as RT-PCR, S1-nuclease protection assay and in situ hybridization, which can detect single copy messages.

\section{LßT2 CT.U6/A CT.U6/B}

- 18.4KDa

$-14.3 \mathrm{KDa}$

\section{GCT1-ASCT-Ab}




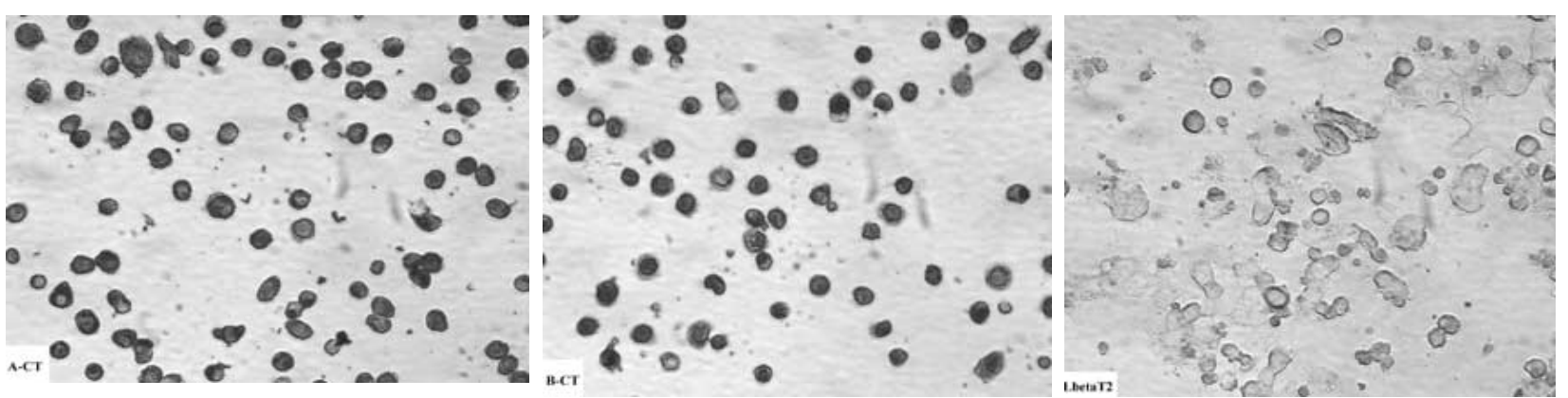

Figure 4 CTI-ICC of L $\beta$ T2 cells and CT.U6 transfectants: L $\beta$ T2 cells as well as CT.U6 (A and B) cell lines were processed for CT ICC as described in the Materials and Methods section. GCT1-anti-SCT serum was used as primary antiserum. Both CT.U6 cell lines (A and B; left and middle panels) stained intensely for CTI. In contrast, L $\beta T 2$ cells (right panel) stained only lightly under the same experimental conditions. Negative controls with preabsorbed antiserum did not display any staining. The experiment was repeated with three different cultures of L $\beta$ T2 and CT.U6 (A and B).

The third objective of the present study was to test whether the translated product of pit-CT cDNA inhibits lactotrope function. Previous evidence has shown that SCT, when administered either centrally or peripherally, inhibits PRL release in rats (Olgiati et al. 1981, 1982, 1983). In vitro experiments from this and other laboratories have extended these earlier findings by demonstrating that SCT acts directly at the level of lactotropes to inhibit PRL release, PRL gene transcription and lactotrope cell proliferation (Shah et al. 1988, 1990, 1993, 1999, Judd et al. 1990, Sortino et al. 1991, Zhang et al. 1995). A role for the endogenous peptide in these processes is demonstrated by the findings that immunoneutralization of pit-CT with GCT1 anti-SCT serum causes a significant

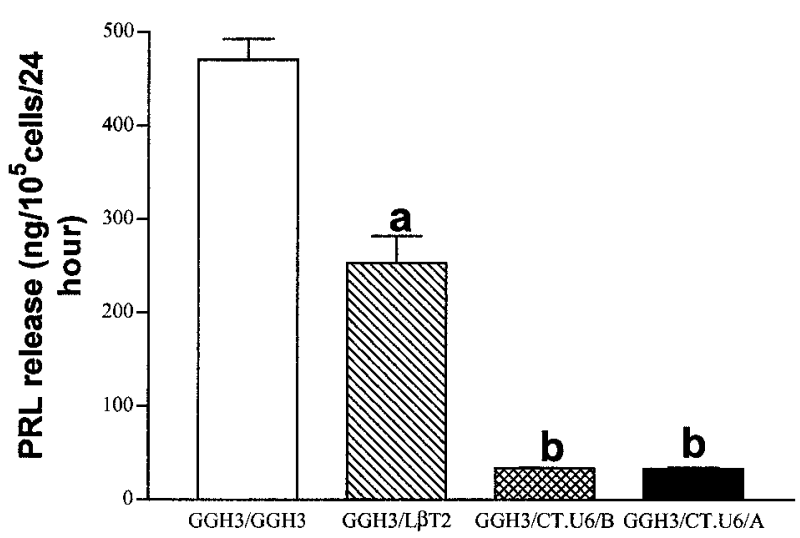

Figure 5 Co-culture with CT.U6 cells dramatically attenuates PRL release from GGH3 cells. GGH3 and L $\beta$ T2/CT.U6 cells were co-cultured with GGH3 cells in transwell culture plates as described in the Materials and Methods section. Spent media were collected after $24 \mathrm{~h}$ of co-cultures and analyzed for PRL by RIA. Controls were GGH3/GGH3 homologous co-cultures. Each data point was run in triplicate, and the experiment was repeated three times. The pooled results are presented as mean ng PRL released \pm S.E.M. $(n=9)$. The results were analyzed by one-way ANOVA and significance was derived by Newman-Keul's test. a, $P<0 \cdot 01$ (GGH3/GGH3 vs L $\beta$ T2/GGH3); b, $P<0 \cdot 001$ (GGH3/GGH3 vs CT.U6 (A and B)/GGH3). increase in PRL release from cultured AP cells as well as in ovariectomized conscious rats (Shah et al. 1993, 1996). Consistent with these findings, the present results show

\section{GGH3/ LßT2/ CTU6.A/ CTU6.B/ GGH3 GGH3 GGH3 GGH3}

PRL

\section{$\beta$-actin}

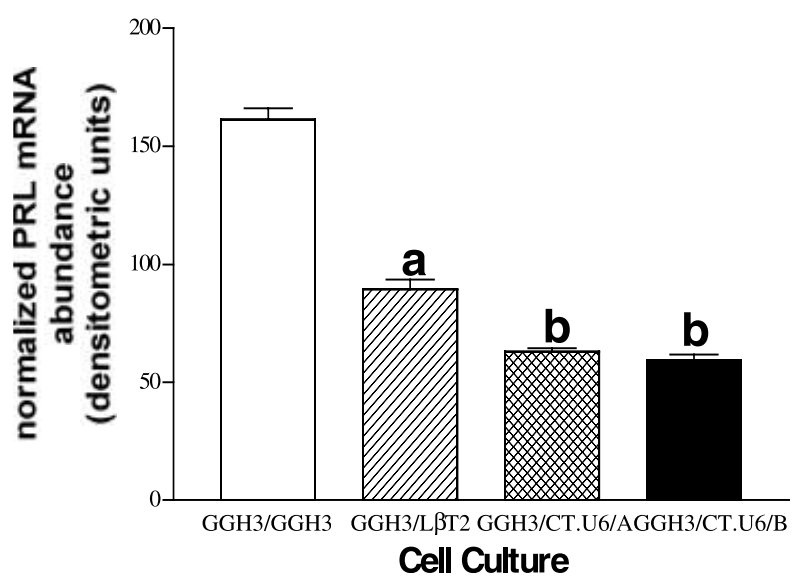

Figure 6 Co-culture with CT.U6 cells causes a marked decrease in PRL mRNA abundance of GGH3 cells. GGH3 and L $\beta$ T2 or CT.U6 ( $\mathrm{A}$ and $\mathrm{B}$ ) cells were co-cultured with $\mathrm{GGH} 3$ cells in transwell culture plates as described in the Materials and Methods section. The GGH3 cells were lysed, RNA was extracted and PRL mRNA abundance was determined by $\mathrm{S} 1$-nuclease protection assay. $\beta$-actin mRNA abundance was also measured. Controls were GGH3/GGH3 homologous co-cultures. The results from three separate experiments were quantified by densitometry, normalized and are expressed as mean \pm S.E.M. densitometric units $(n=6)$. The data were statistically analyzed by one-way ANOVA, and significance was derived by Newman-Keul's test. a, $P<0.01$ (GGH3/GGH3 vs L $\beta T 2$ / $\mathrm{GGH} 3) ; b, P<0 \cdot 001(\mathrm{GGH} 3 / \mathrm{GGH} 3$ vs CT.U6 (A and $\mathrm{B}) / \mathrm{GGH} 3)$. 


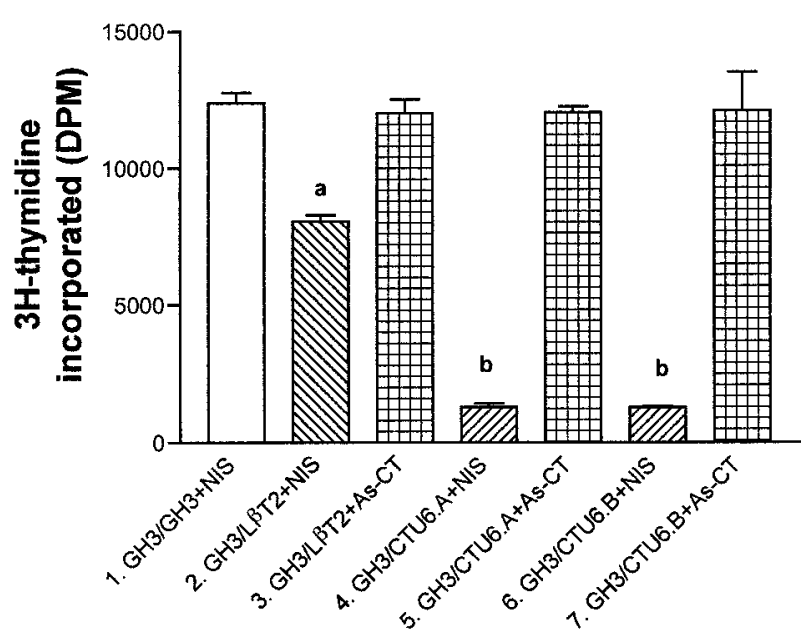

Figure 7 Co-culture with CT.U6 cells causes a dramatic decline in DNA synthesis of $\mathrm{GH} 3$ cells. GGH3 and L $\beta$ T2 or CT.U6 (A and B) cells were co-cultured with GGH3 cells in transwell culture plates as described in the Materials and Methods section. In addition, the cells received either non-immune serum (NIS, 1:50) or GCT1-anti SCT serum (As-CT, 1:50). The GGH3 cells were treated with $0 \cdot 5 \mu \mathrm{Ci}\left[{ }^{3} \mathrm{H}\right]$ thymidine during the last four hours. The cells were lysed and the incorporated $\left[{ }^{3} \mathrm{H}\right]$ thymidine was determined. Each experimental data point was run in quadruplicate, and the experiments were repeated three separate times. The results are expressed as mean $\left[{ }^{3} \mathrm{H}\right]$ thymidine incorporated \pm S.E.M. $(n=12)$. The results were further analyzed by one-way ANOVA and Newman-Keul's test. a, $P<0 \cdot 01$ (GGH3/GGH3 vs L $\beta$ T2/GGH3); b, $P<0.001(\mathrm{GGH} 3 / \mathrm{GGH} 3$ vs CT.U6 (A and $\mathrm{B}) / \mathrm{GGH} 3)$.

that stable pit-CT transfectants secrete high concentrations of GCT1-reactive CTI, and they markedly inhibit PRL secretion, PRL mRNA abundance, and also attenuate proliferation of GGH3 cells. A role of pit-CT in these effects is implicated by the findings that GCT1-anti-SCT serum severely attenuates this inhibition.

There is accumulating evidence for the role of paracrine/autocrine peptides in the function of the AP gland. Different cell types display different proportions in the AP gland, and their relative proportions change continuously with changing hormonal environment. For example, there is a dramatic increase in lactotrope cell populations during pregnancy and lactation (Aoki et al. 1994). There is also a drastic decrease in these populations with the cessation of lactation (Orgenero de Gaisen et al. 1993). Moreover, pituitary cell types respond to hormonal stimuli differently in different physiological conditions or hormonal milieu (Pasolli et al. 1992, Aoki et al. 1994, De Paul et al. 1997). The evidence suggests that signals provided by gonadal or neuroendocrine hormones to their target AP cells may be amplified or modulated by paracrine/autocrine factors. For example, pituitaryderived vasoactive intestinal polypeptide (VIP) and galanin stimulate PRL secretion and also induce lactotrope proliferation (Kaplan et al. 1988, Hsu et al. 1990, Wynik et al. 1993, 1998, Carretero et al. 1995, Balsa et al. 1996, 1998).
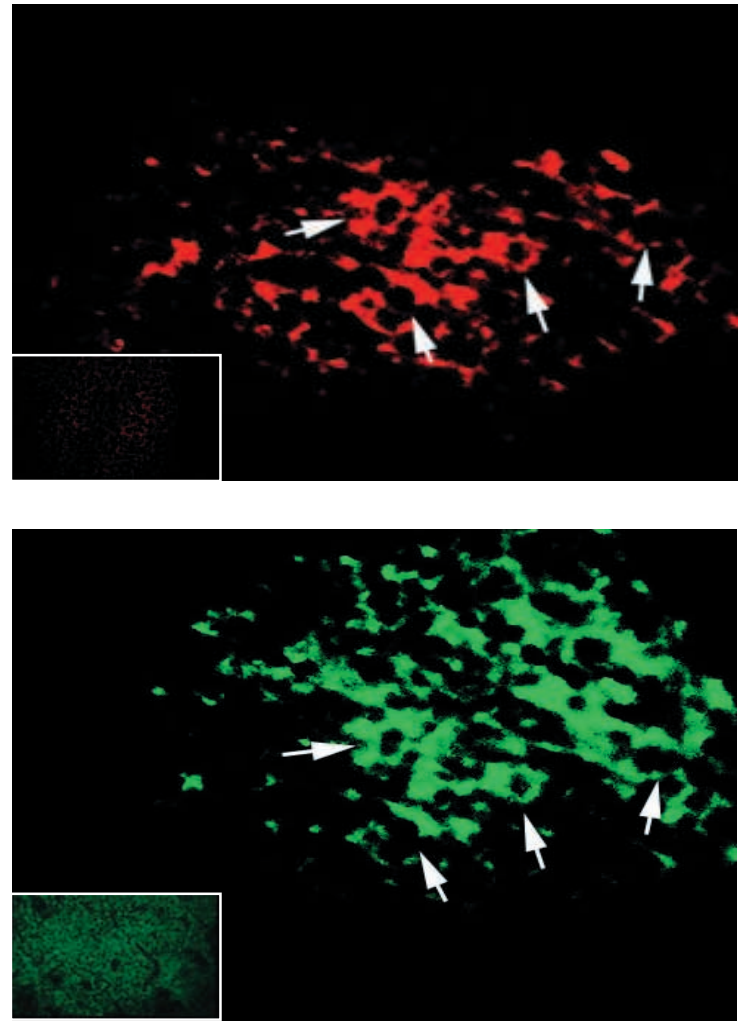

Figure 8 Co-localization of CT mRNA with $\beta$-LH mRNA in rat AP gland. Fluorescent probes for $\beta$-LH mRNA (TRITC) and CT mRNA (FITC) were prepared as described in the Materials and Methods section. Frozen rat AP sections ( $5 \mu \mathrm{m}$ thick) were hybridized with these probes. Arrowheads in a typical micrograph depict colocalization of $\beta$-LH mRNA (red, upper panel) and CT mRNA (green, lower panel) in the same cells. Sense controls are presented in the inset. Magnification: $\times 400$.

It has been suggested that several effects of estrogens on lactotrope function and proliferation are mediated by lactotrope-derived VIP and galanin (Wynik et al. 1993, Cai et al. 1998). Similarly, our studies suggest that CT inhibits PRL release and PRL gene transcription, and also attenuates thyrotropin-releasing hormone (TRH)- and suckling-induced PRL release and synthesis (Shah et al. 1988, 1990, Judd et al. 1990). CT is also a potent inhibitor of lactotrope proliferation (Shah et al. 1999). Expression of pit-CT is almost undetectable in early and mid-lactation but displays a dramatic increase in late lactation (Chronwall et al. 1996). Moreover, estrogens, which stimulate PRL synthesis and lactotrope proliferation, attenuate CT expression in the AP gland ( $\mathrm{Li} \&$ Shah 1995). Considering the secretion of CT by gonadotropes and the antagonistic functional relationships between gonadotropes and lactotropes, these results raise the strong possibility that gonadotropes may remodel the AP gland by modulating lactotrope cell number and function through the secretion of CT. 


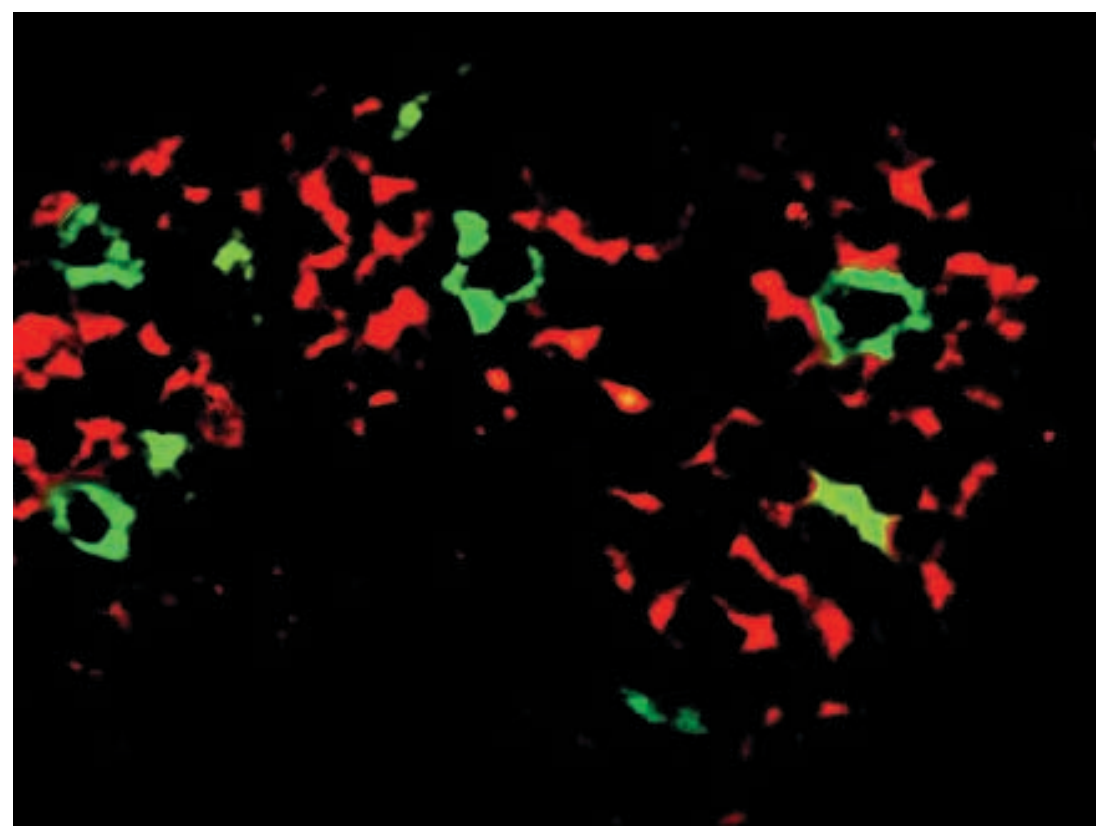

Figure 9 Localization of CT and PRL mRNAs in rat AP gland. The AP sections were hybridized simultaneously with PRL and CT mRNA probes as described in the Materials and Methods section. A typical micrograph shows that the AP cells labeled either for PRL mRNA (red) or for CT mRNA (green), and co-localization of both mRNAs in the same cells was not observed. However, most CT mRNA cells seemed to have been surrounded by PRL mRNA cells. Magnification: $\times 400$.

In conclusion, we have cloned pit-CT cDNA from the gonadotrope-derived L $\beta \mathrm{T} 2$ cell line, and its sequence shows close homology to mouse CT mRNA. Pit-CT mRNA has been localized to gonadotropes, and the encoded peptide may regulate lactotrope function. The availability of the pit-CT cDNA will facilitate further investigations on the role of pit-CT in regulation of the AP gland.

\section{Acknowledgements}

The authors gratefully acknowledge Drs Pam Mellon (UCSD) and Michael Conn (ORPRC) for L $\beta T 2$ and GGH3 cell lines respectively. We also acknowledge Dr A F Parlow and the National Hormone Program and NIDDK for providing the rPRL RIA kit. This work was supported by grant DK-45044 from NIDDK, NIH.

\section{References}

Albrandt K, Mull E, Brady EM, Herich J, Moore CX \& Beaumont K 1993 Molecular cloning of two receptors from rat brain with high affinity for salmon calcitonin. FEBS Letters 325 225-232.

Aoki A, Pasolli HA \& Torres AI 1994 Pituitary plasticity as correlate of secretory activity. Experimental and Toxicologic Pathology $\mathbf{4 6}$ $435-436$.
Azria M 1989 The Calcitonins. Basel, Switzerland: Karger.

Balabanova S, King O, Nowak R, Sachs H \& Leupold D 1985 Immunoreactive calcitonin in brain regions and pituitary of sheep. Journal of Endocrinological Investigation 8 409-415.

Balsa JA, Cacicedo L, Lara JI, Lorenzo MJ, Pazos F \& Sanchez-Franco F 1996 Autocrine and/or paracrine action of vasoactive intestinal peptide on thyrotropin-releasing hormone induced prolactin release. Endocrinology 137 144-150.

Balsa JA, Sanchez-Franco F, Pazos F, Lara JI, Lorenzo MJ, Maldonado G \& Cacicedo L 1998 Direct action of serotonin on prolactin, growth hormone, corticotropin and luteinizing hormone release in cocultures of anterior and posterior pituitary lobes: autocrine and/or paracrine action of vasoactive intestinal peptide. Neuroendocrinology 68 326-333.

Cai A, Bowers RC, Moore JP Jr \& Hyde JF 1998 Function of galanin in the anterior pituitary of estrogen-treated Fischer 344 rats: autocrine and paracrine regulation of prolactin secretion. Endocrinology 139 2452-2458.

Carretero J, Rubio M, Sanchez F, Vazquez RJ, Santos M, Blanco J \& Vazquez R 1995 In vitro morphometric and proliferative variations in VIP-immunoreactive pituitary cells induced by estradiol. Neuroendocrinology 62 277-282.

Chien J, Wong E, Nikes E, Noble MJ, Pantazis CG \& Shah GV 1999 Constitutive activation of stimulatory guanine nucleotide binding protein $(\mathrm{G}(\mathrm{S})$ alphaQL)-mediated signaling increases invasiveness and tumorigenicity of PC-3M prostate cancer cells. Oncogene 18 3376-3382.

Chronwall BM, Sands SA, Li Z \& Shah GV 1996 Calcitonin-like peptide containing gonadotrophs are juxtaposed to cup-shaped lactotrophs. Endocrine Journal 4 27-33.

Cooper CW, Peng TC, Obie JF \& Garner SC 1980 Calcitonin-like immunoreactivity in rat and human pituitary glands: histochemical, in vitro and in vivo studies. Endocrinology 107 98-107. 
De Paul AL, Pons P, Aoki A \& Torres AI 1997 Heterogeneity of pituitary lactotrophs: immunocytochemical identification of functional subtypes. Acta Histochemica 99 277-289.

Deftos LJ 1987 Pituitary cells secrete calcitonin in the reverse hemolytic plaque assay. Biochemical and Biophysical Research Communications 146 1350-1356.

Deftos LJ, Burton D, Catherwood BD, Bone HG, Parthemore JG, Guillemin R, Watkins WB \& Moore RY 1978 Demonstration by immunoperoxidase histochemistry of calcitonin in the anterior lobe of the rat pituitary. Journal of Clinical Endocrinology and Metabolism 47 457-460.

Feinberg AP \& Vogelstein B 1983 A technique for radiolabeling DNA restriction endonuclease fragments to high specific activity. Analytical Biochemistry 132 6-13.

Fischer JA \& Born W 1985 Novel peptides from the calcitonin gene: expression, receptors and biological function. Peptides 6 (Suppl 3) 265-271.

Fischer JA, Tobler PH, Kaufmann M, Born W, Henke H, Cooper PE, Sagar SM \& Martin JB 1981 Calcitonin: regional distribution of the hormone and its binding sites in the human brain and pituitary. PNAS 78 7801-7805.

Fischer JA, Tobler PH, Henke H \& Tschopp FA 1983 Salmon and human calcitonin-like peptides coexist in the human thyroid and brain. Journal of Clinical Endocrinology and Metabolism $\mathbf{5 7}$ 1314-1316.

Flynn JJ, Margules DL \& Cooper CW 1981 Presence of immunoreactive calcitonin in the hypothalamus and pituitary lobes of rats. Brain Research Bulletin 6 547-549.

Gagel RF, O'Briain DS, Voelkel EF, Wolfe HJ, DeLellis RA, Lee AK \& Tashjian AH Jr 1983 Pituitary immunoreactive calcitonin-like material: lack of evidence for cross-reactivity with pro-opiomelanocortin. Metabolism 32 686-696.

Henke H, Tobler PH \& Fischer JA 1983 Localization of salmon calcitonin binding sites in rat brain by autoradiography. Brain Research 272 373-377.

Hilton JM, Mitchelhill KI, Pozvek G, Dowton M, Quiza M \& Sexton PM 1998 Purification of calcitonin-like peptides from rat brain and pituitary. Endocrinology 139 982-992.

Hsu DW, el Azouzi M, Black PM, Chin WW, Hedley Whyte ET \& Kaplan LM 1990 Estrogen increases galanin immunoreactivity in hyperplastic prolactin-secreting cells in Fisher 344 rats. Endocrinology 126 3159-3167.

Iczkowski KA, Pantazis CG, Long J, Noble MJ \& Shah GV 1998 Expression of calcitonin-like peptide is increased in prostatic adenocarcinoma. Journal of Urologic Pathology 8 135-147.

Jacobs JW, Goltzman D \& Habener JF 1982 Absence of detectable calcitonin synthesis in the pituitary using cloned complementary deoxyribonucleic acid probes. Endocrinology 111 2014-2019.

Judd AM, Kubota T, Kuan SI, Jarvis WD, Spangelo BL \& MacLeod RM 1990 Calcitonin decreases thyrotropin-releasing hormone-stimulated prolactin release through a mechanism that involves inhibition of inositol phosphates production. Endocrinology 127 191-199.

Kaplan LM, Gabriel SM, Koenig JI, Sunday ME, Spindel ER, Martin JB \& Chin WW 1988 Galanin is an estrogen-inducible, secretory product of the rat anterior pituitary. PNAS 85 7408-7412.

Li Z \& Shah GV 1995 Estrogen attenuates expression of calcitonin-like immunoreactivity in the anterior pituitary gland. Endocrine Journal 3 452-459.

Margules DL, Flynn JJ, Walker J \& Cooper CW 1979 Elevation of calcitonin immunoreactivity in the pituitary and thyroid glands of genetically obese rats $(\mathrm{fa} / \mathrm{fa})$. Brain Research Bulletin 4 589-591.

Olgiati VR, Guidobono F, Luisetto G, Netti C, Bianchi C \& Pecile A 1981 Calcitonin inhibition of physiological and stimulated prolactin secretion in rats. Life Science 29 585-594.
Olgiati VR, Netti C, Guidobono F \& Pecile A 1982 High sensitivity to calcitonin of prolactin-secreting control in lactating rats. Endocrinology 111641 - 644.

Olgiati VR, Guidobono F, Netti C \& Pecile A 1983 Localization of calcitonin binding sites in rat central nervous system: evidence of its neuroactivity. Brain Research 265 209-215.

Orgenero de Gaisen EM, Maldonado CA \& Aoki A 1993 Fate of degenerating lactotropes in rat pituitary gland after interruption of lactation: a histochemical and immunocytochemical study. Histochemical Journal 25 150-165.

Pasolli HA, Torres AI \& Aoki A 1992 Influence of lactotroph cell density on prolactin secretion in rats. Journal of Endocrinology 134 241-246.

Potts JT Jr 1976 Chemistry of calcitonins. In Handbook of Physiology, pp 423-437. Ed GD Aurbach. Washington DC, USA: American Physiology Society.

Rehli M, Luger K, Beier W \& Falk W 1996 Molecular cloning and expression of mouse procalcitonin. Biochemical and Biophysical Research Communications 226 420-425.

Sexton PM \& Hilton JM 1992 Biologically active salmon calcitoninlike peptide is present in rat brain. Brain Research 596279 284.

Sexton PM, Houssami S, Hilton JM, O'Keeffe LM, Center RJ, Gillespie MT, Darcy P \& Findlay DM 1993 Identification of brain isoforms of the rat calcitonin receptor. Molecular Endocrinology 7 815-821.

Shah GV, Epand RM \& Orlowsky RC 1988 Calcitonin inhibits prolactin secretion in isolated rat pituitary cells. Journal of Endocrinology 116 279-286.

Shah GV, Kacsoh B, Seshadri R, Grosvenor CE \& Crowley WR 1989 Presence of calcitonin-like peptide in rat milk: possible physiological role in regulation of neonatal prolactin secretion. Endocrinology 125 61-67.

Shah GV, Wang W, Grosvenor CE \& Crowley WR 1990 Calcitonin inhibits basal and thyrotropin-releasing hormone-induced release of prolactin from anterior pituitary cells: evidence for a selective action exerted proximal to secretogogue-induced increases in cytosolic $\mathrm{Ca}^{2+}$. Endocrinology 132 621-628.

Shah GV, Deftos LJ \& Crowley WR 1993 Synthesis and release of calcitonin-like immunoreactivity by anterior pituitary cells: evidence for a role in paracrine regulation of prolactin secretion. Endocrinology 132 1367-1372.

Shah GV, Pedchenko V, Stanley S, Li Z \& Samson WK 1996 Calcitonin is a physiological inhibitor of prolactin secretion in ovariectomized female rats. Endocrinology 137 1814-1822.

Shah GV, Chien J, Sun YP, Puri S \& Ravindra R 1999 Calcitonin inhibits anterior pituitary cell proliferation in the adult female rats. Endocrinology 140 4281-4291.

Sheward WJ, Lutz EM \& Harmar AJ 1994 The expression of the calcitonin receptor gene in the brain and pituitary gland of the rat. Neuroscience Letters 181 31-34.

Sortino MA, Canonico PL \& Clementi G 1991 Bimodal action of [Asu1,7]eel-calcitonin on phosphoinositide hydrolysis in cultured anterior pituitary cells. European Journal of Pharmacology 207 345-350.

Stevenson JC 1980 The structure and function of calcitonin. Investigative and Cell Pathology 3 187-193.

Thomas P, Mellon PL, Turgeon J \& Waring DW 1996 The L beta T2 clonal gonadotrope: a model for single cell studies of endocrine cell secretion. Endocrinology 137 2979-2989.

Watkins WB \& Moore RY 1980 Immunoreactive calcitonin in the rat anterior pituitary gland and its localization in thyrotrophs. American Journal of Anatomy 158 445-454.

Wynik D, Hammond PJ, Akinsaya KO \& Bloom SR 1993 Galanin regulates basal and estrogen-stimulated lactotroph function. Nature 364 529-532. 
Wynik D, Small CJ, Bacon A, Holmes FE, Norman M, Ormandy CJ, Kilic E, Kerr NC, Ghatei M, Talamantes F, Bloom SR \& Pachnis V 1998 Galanin regulates prolactin release and lactotroph proliferation. PNAS 95 12671-12676.

Xie WQ \& Rothblum LI 1991 Rapid, small-scale RNA isolation from tissue culture cells. Biotechniques 11 324-327.
Zhang Q, Stanley SM \& Shah GV 1995 Calcitonin inhibits prolactin gene transcription in rat pituitary cells. Endocrine Journal 3 445-451.

Received in final form 11 July 2001 Accepted 18 July 2001 